\title{
Serviço Social e Ministério Público: aproximações mediadas pela defesa e garantia de direitos humanos*
}

\section{Social Work and Department of Justice: approaches mediated by the defense and guarantee of human rights}

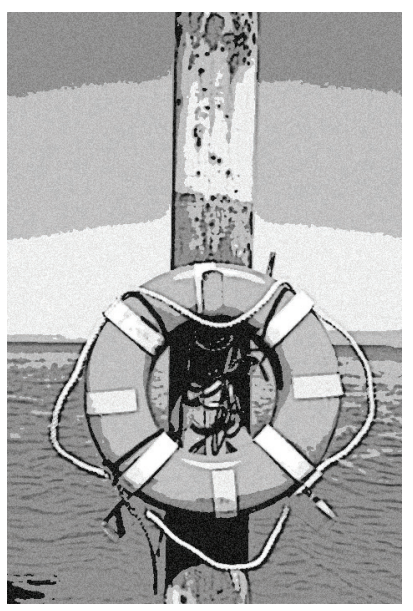

\section{Silvia da Silva Tejadas**}

Resumo: Este artigo aborda a emergência do Ministério Público na esfera pública, balizado pela missão, ainda em disputa na instituição, de defesa do regime democrático e dos direitos humanos. A inserção do Serviço Social na Instituição é atravessada pelas contradições que a permeiam e compartilha de propósitos convergentes à sua missão, dado o projeto ético-político-profissional. Apresenta potencial para contribuir no diálogo com os movimentos sociais e conselhos de direitos, bem como no fomento e na fiscalização das políticas públicas, fundamentado em um ideário emancipatório.

Palavras-chave: Ministério Público. Serviço Social. Direitos humanos.

* Este artigo teve como ponto de partida a tese de doutorado da autora, publicada com o título $O$ direito humano à proteção social e sua exigibilidade: um estudo a partir do Ministério Público (2012), tendo sido o texto original acrescido de dados atualizados sobre os encontros nacionais do Serviço Social no Ministério Público, bem como de considerações sobre as atribuições da profissão na instituição em questão. A investigação, de cunho qualitativo, fundamentou-se no materialismo histórico e dialético, constituindo-se em estudo de caso. Para o estudo, utilizaram-se as seguintes fontes: grupo focal com assistentes sociais; questionário com coordenadores de Centros de Apoio de diversos estados; 234 artigos de promotores, procuradores de Justiça e 45 artigos de assistentes sociais, apresentados em congressos e encontros do Ministério Público; documentos e pesquisas sobre a instituição. O objetivo central do estudo foi analisar a atuação do Ministério Público estadual na exigibilidade da proteção social brasileira após 1988, quando a Constituição Federal o incumbe da defesa dos interesses sociais, individuais indisponíveis e do regime democrático.

** Doutora em Serviço Social pela Pontifícia Universidade Católica do Rio Grande do Sul, Porto Alegre/ RS, Brasil. Especialista em Família pela Clínica Domus e em Educação de Jovens e Adultos, na Perspectiva da Educação Popular pela Universidade Federal do Rio Grande do Sul. Desde 2002 é assistente social do Ministério Público do Rio Grande do Sul.E-mail: silviast@mp.rs.gov.br. 


\begin{abstract}
This article approaches the emergence of the Department of Justice in the public sphere. Such emergence is oriented by the mission (which is still in dispute in the institution) of defending the democratic regime and the human rights. The insertion of Social Work in the institution is crossed by the contradictions that permeate it and share the purposes of the mission of the institution, given its ethical-political-professional project. It shows potential to contribute to the dialogue with the social movements and rights councils, as well as to the increase and inspection of public politics, as it is marked by emancipatory ideas.
\end{abstract}

Keywords: Department of Justice. Social Work. Human Rights.

\title{
1. Introdução
}

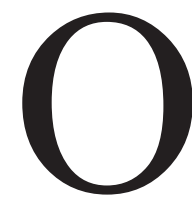

presente artigo aborda o recente processo histórico de inserção do Serviço Social no Ministério Público brasileiro, instituição incumbida pela Constituição Federal de 1988 da defesa do regime democrático e dos interesses individuais indisponíveis e sociais. A partir do final de década de 1990, desencadeia-se um movimento de contratação de assistentes sociais na instituição, o que se acentuou na década de 2000 . Tendo em vista percurso histórico tão recente, abrem-se múltiplas possibilidades de qualificar e direcionar o exercício profissional nesse espaço sócio-ocupacional.

Inicialmente, situa-se de modo breve o processo histórico do Ministério Público até a assunção da missão insculpida no artigo 127 da Constituição Federal, oferecendo, ainda, uma visão geral acerca da instituição e de seus desafios. Em seguida, são discutidos os caminhos que o Serviço Social vem percorrendo na instituição, as demandas, as requisições, a direção social que a profissão vem delineando, seus principais limites e possibilidades.

São tecidas possibilidades para as atribuições do Serviço Social no Ministério Público, à luz do projeto ético-político-profissional, que tenham potencial para contribuir com as lutas sociais pela defesa e garantia dos direitos humanos. Ao final, sinalizam-se os desafios organizativos para a profissão e as alianças necessárias para que o Serviço Social contribua na aproximação do Ministério Público aos propósitos definidos pela Constituição Federal. 


\section{A emergência do ministério público como instituição de defesa de direitos}

As origens da instituição Ministério Público revelam seu surgimento com o advento da Revolução Francesa, em 1789, e da Declaração dos Direitos do Homem e do Cidadão, quando os reis deixaram de realizar a justiça pessoalmente, delegando tal função ao magistrado. Nessas circunstâncias, surgiu a necessidade de um órgão fiscalizador ao juiz - o Ministério Público (Maia Neto, 1999). Seu nascedouro o coloca no lugar de acusador, a princípio como representante do interesse do monarca e, depois, especialmente a partir do século XVIII, com o liberalismo, passou a representar os interesses da sociedade no papel acusatório (Porto, 2006).

No Brasil, figura mais próxima ao representante do Ministério Público surgiu no Brasil Colônia, nas disposições contidas nas Ordenações Filipinas. Naquele período histórico, o Ministério Público não existia como instituição, os promotores públicos da época eram nomeados e exonerados livremente pelos presidentes das províncias e vinculavam-se ao Poder Executivo (Maia Neto, 1999). A figura do promotor público passou a existir com a Lei n. 261, de 3/12/1841 (reforma do Código de Processo Criminal), mas a existência formal da instituição está vinculada ao Decreto Federal n. 1.030, de 1890, no início da República, no governo do marechal Deodoro da Fonseca (Maia Neto, 1999).

Os apontamentos históricos acerca do processo de constituição do Ministério Público permitem identificar correlações entre o papel destacado ou restrito e o período histórico. Nesse sentido, nas ditaduras civil e militar, por exemplo, constata-se uma restrição na atuação e importância social da instituição, observando-se o contrário nos períodos de maior abertura política.

A Constituição Federal de 1988 diferenciou-se das demais por definir o Ministério Público com maior precisão: garantindo-lhe autonomia funcional e administrativa; estabelecendo critérios formais para a escolha do procurador-geral da República e dos estados; permitindo a exclusividade da promoção da ação penal, bem como ampliando a titularidade para o inquérito civil e para a ação civil pública no que concerne aos interesses difusos e coletivos (Porto, 2006).

Assim, no decorrer do processo histórico, as funções do Ministério Público foram se modificando, sendo hoje caracterizado como instituição voltada para a 
defesa dos interesses da sociedade, no que diz respeito aos direitos difusos, individuais indisponíveis e sociais. ${ }^{1}$

Ritt (2002), ao analisar o papel do Ministério Público, constituído recentemente, ressalta que as garantias conquistadas pela instituição, como a independência funcional, vitaliciedade, inamovibilidade e irredutibilidade de subsídios, passando a ser considerada, por alguns, como poder de Estado, não vêm necessariamente acompanhadas de um entendimento claro de sua missão institucional e da consequente importância na realização de uma sociedade justa e igualitária.

Já para Porto (2006), o paradoxo vivido pelo Ministério Público reside na assunção da missão de defesa dos interesses coletivos, ao mesmo tempo em que conserva a condição de instituição estatal. Defende o referido autor que o Ministério Público transitou da sociedade política para a sociedade civil, a partir da visão gramsciana de Estado, por três razões: a social, devido à vocação de atuar na defesa da sociedade; a política, pelo compromisso assumido na história de defesa da democracia e de suas instituições; a jurídica, em razão das garantias constitucionais.

As reflexões dos autores citados, sem dúvida, conferem relevo aos dilemas contemporâneos da instituição, uma vez que ela passou a assumir importância para o conjunto da sociedade, sem estar plenamente preparada para tanto. O papel de zelar pelos direitos coletivos, ou seja, pelos interesses da maioria da sociedade e, em especial, daqueles segmentos mais vulnerabilizados pela pobreza e por formas variadas de discriminação, implica agregar novos conhecimentos sobre o sistema de proteção social, sobre o funcionamento e a estrutura das políticas públicas, sobre habilidades de negociação e de debate com distintos atores sociais. Isso leva a concluir que a instituição passa a necessitar de promotores e procuradores de justiça e servidores com novas competências e habilidades que se coadunem com sua missão institucional, o que, por certo, é um processo em construção.

1. Nessa seara, Mazzilli (1998) esclarece os interesses definidos legalmente, distinguindo-os quanto à disponibilidade e à titularidade. No primeiro caso, disponíveis são os interesses de maiores e capazes, como os patrimoniais, e indisponíveis são direitos como os relativos à vida e à liberdade. Já com relação à titularidade, têm-se interesses: individuais; individuais homogêneos (grupo de pessoas que partilham de prejuízos divisíveis decorrentes de uma mesma circunstância); coletivos no sentido estrito (grupo de pessoas determináveis que partilham de prejuízos indivisíveis decorrentes de uma mesma relação jurídica); difusos (grupo de pessoas indetermináveis com danos indivisíveis e reunidas pelas mesmas circunstâncias do fato); interesse público em sentido estrito (Estado é o titular, se distingue do interesse privado); interesse público em sentido lato. 
A autonomia e a independência funcional visam conferir à instituição, no âmbito do estado democrático de direito, uma atuação não subjugada a interesses de governos ou de qualquer outro dispositivo de poder presente na sociedade. Nessa esteira, o Ministério Público tem o dever de agir quando os segmentos mais vulnerabilizados e enfraquecidos na luta política apresentam necessidades não supridas, como crianças e adolescentes, idosos, interditos, pessoas com deficiência, entre outros, tendo um papel ativo na defesa de direitos.

O regime democrático exige dos agentes do Poder Público atuação em defesa dos interesses gerais e indisponíveis dos cidadãos. A realização efetiva da Justiça é alvo da instituição do Ministério Público. O promotor de Justiça, como seu representante, é um verdadeiro justitie-ombudsman, delegado permanente da coletividade, advogado por excelência da sociedade, que vela pela correta aplicação da lei e funciona como instância de tutela individual e coletiva de cidadania. (Maia Neto, 1999, p. 35)

Nesse contexto, há uma corrente percepção institucional de que é mais produtiva a intervenção em situações de não garantia de direitos no âmbito extrajudicial, visto que a jurisdicionalização de causas pode se estender por longos períodos. Rojo (2003, p. 25) ratifica tal assertiva quando refere que

a jurisdicionalização pode surtir o efeito contrário e transformar-se em um mecanismo que ajude a postergar as decisões. Com efeito, este recurso à lei e seus magistrados pode permitir ao poder político criar uma aparência de tratamento do assunto, quando em realidade o que ele consegue é suspender a resolução deslocando as demandas a um espaço supostamente técnico onde os cidadãos teriam mais dificuldades para controlar ou apressar sua evolução.

Dessa forma, a jurisdicionalização de conflitos é matéria controversa que, se por um lado pode constituir-se em meio de assegurar direitos, por outro pode mascarar negativas de direitos e, mais do que isso, institucionalizar possíveis lutas sociais, que teriam maior êxito se desenvolvidas no contexto social no qual se produzem.

Nesse diapasão, o Ministério Público está imerso em relações sociais, e sua aproximação ou afastamento da missão atribuída constitucionalmente encontra conexão com interesses, projetos políticos e relações que se estabelecem e que estão em disputa. Entre relações e projetos, o Ministério Público emerge do texto constitucional com a potência de criar novas hegemonias, em direção a uma socie- 
dade mais igualitária, em que os frutos do desenvolvimento das forças produtivas sejam compartilhados entre todos. Todavia, o novo emerge emaranhado ao velho. O Ministério Público é incumbido de uma missão que não foi apropriada internamente por todos os seus membros, evidenciando-se a disputa pela hegemonia da direção social da instituição.

A missão constitucional do Ministério Público se efetivará na medida em que a instituição for capaz de dialogar com os diferentes atores que compõem a esfera pública, portadores de interesses e projetos políticos distintos. Assim, não lhe basta a vontade de constituir-se em um articulador da garantia dos direitos humanos, pois esta é apenas parte; há, ainda, as circunstâncias (Nogueira, 2004). A explicitação de interesses e projetos, o desvendamento de sua essência, no claro-escuro do real, e a sua apreensão pelos agentes ministeriais são essenciais. A visão de totalidade, a conexão entre os fragmentos do real e a compreensão crítica da correlação de forças é que dará qualidade política à intervenção do Ministério Público, por meio de sua preparação para o diálogo entre os atores que interagem na esfera pública. Isso desafia o Ministério Público a construir dispositivos analíticos direcionados a essas realidades complexas, que permitam o dimensionamento de estratégias e posicionamentos em favor daqueles interesses que se coadunam com os direitos humanos a ser garantidos por meio das políticas públicas.

Ao atribuir-se significado a essas relações percebe-se que elas são atravessadas por contradições. Constata-se que a instituição vive, nas suas relações com os demais atores da esfera pública, uma tensão fundante entre a posição de fiscal e a de parceiro, que acaba por se expressar na ambiguidade da identidade institucional. A partir dessa ambiguidade, identificam-se tendências distintas das relações estabelecidas, as quais podem ser agrupadas de forma reguladora e dialógica. A primeira, amparada em perspectiva iluminista, coloca a instituição no lugar do saber, portanto capaz de oferecer saídas, orientar, conduzir as relações ou de lançar mão de mecanismos coercitivos. Essa tendência revela a dificuldade em transitar em meio a uma dinâmica complexa de relações e interesses, vislumbrando como alternativa o uso do lugar de autoridade da instituição. A segunda, que pode ser alinhada com uma ideia de direção político-cultural, volta-se para a construção de mecanismos educativos, com potencial para a indução de políticas públicas. Essas tendências nem sempre se apresentam na realidade de modo límpido; por vezes estão imbricadas nas experiências cotidianas.

É necessário reconhecer que a própria missão atribuída ao Ministério Público na Constituição coloca-o em lugar de centralidade. Esse lugar convida à postura 
iluminista, ao caminho da arrogância e do messianismo. Por outro lado, essa missão dá-se no âmbito do estado democrático de direito, que tensiona para a construção de direções hegemonicamente edificadas, ou seja, requer capacidade de dirigir técnica e politicamente, de construir consensos (Nogueira, 2004) e "saídas" alicerçadas coletivamente. As situações, individuais e coletivas, que aportam ao Ministério Público, são dotadas de complexidade, pois manifestam as ausências e as negações de direitos. Esse contexto insta à oscilação entre a impotência e o messianismo, o que é um risco às relações e à atuação institucional, pois ambas as posições podem conduzir à omissão e a comportamentos antidemocráticos.

No entanto, os achados da pesquisa realizada indicam que o reconhecimento dos diferentes interesses e a capacidade de negociação, sem transigir nos direitos a serem garantidos, podem auxiliar na convergência de direção social. Nessa perspectiva, os caminhos escolhidos para a ação devem fortalecer a democracia e a corresponsabilidade dos atores envolvidos, alcançando a pactuação de acordos que conduzam à afirmação dos direitos. Assim, a atuação institucional na direção das políticas públicas, capazes de disponibilizar os direitos assegurados no plano legal é, sem dúvida, um caminho profícuo para a consecução da sua missão, mas encontra, nas relações estabelecidas, a sua potência e a sua fraqueza.

Identificam-se duas vertentes no que concerne às políticas públicas: a do fomento e a da fiscalização. No caso do fomento, evidencia-se que o guia para a ação institucional são os direitos garantidos legalmente e ainda não efetivados, constituindo-se numa agenda de direitos. A fiscalização das políticas públicas, por sua vez, relaciona-se com a qualidade da política pública, evidenciando que não basta a oferta de programas, projetos e serviços correlacionados a direitos; é preciso avaliar sua qualidade e correspondência aos direitos assegurados. Dessa forma, a fiscalização é dotada de expressiva complexidade, pois conduz o Ministério Público ao âmago das políticas, à sua gestão, aos paradigmas que as definem, aos seus processos cotidianos de trabalho.

Tanto a atuação rumo ao fomento das políticas públicas quanto a sua fiscalização indicam a necessidade de que a instituição esteja devidamente apoiada por equipes técnicas multidisciplinares, qualificadas quanto à concepção e ao funcionamento das políticas públicas, o que requer determinado arcabouço de conhecimentos técnicos. Além disso, pede o planejamento das ações institucionais, visto que o fomento e a fiscalização são incompatíveis com ações voluntaristas e condicionadas aleatoriamente às demandas externas, pois são atividades que requerem especialização e direcionamentos claros dos trabalhos, em termos metodológicos 
e de suas finalidades. É nesse contexto desafiador e complexo que o Serviço Social vem atuando desde meados da década de 1990, sendo essa caminhada objeto de análise do próximo item.

\section{0 processo de inserção do Serviço Social no Ministério Público}

O Serviço Social é uma profissão com inserção recente no Ministério Público e fruto do processo de mudança vivido pela instituição quanto à assunção da missão de defesa dos direitos individuais indisponíveis e sociais. Identifica-se a consonância entre a missão institucional quanto à garantia de direitos humanos e o projeto ético-político-profissional, sendo aqui apontadas algumas das construções coletivas da categoria no Ministério Público e, ainda, seus limites e desafios.

Inicia-se pela discussão e apresentação da categoria demandas, pois estas expressam a intencionalidade da instituição ao incorporar os assistentes sociais em seus quadros. Identifica-se que as demandas encaminhadas aos profissionais são as mais diversas; porém, quanto ao âmbito da intervenção, é possível reuni-las em dois grupos: em situações individuais e em matérias de direito difuso e coletivo. $\mathrm{O}$ primeiro grupo envolve o estudo social, subsidiando os promotores de justiça quanto à condução de violações de direitos nesse âmbito; o outro, atividades relativas à exigibilidade de políticas públicas, tais como: fiscalização, fomento, acompanhamento, controle e avaliação; realização de estudos e pesquisas sobre determinada realidade; articulação política relativa à promoção de diálogos, firmatura de pactos, termos e parcerias para garantir direitos/cumprimento de políticas públicas; vistorias em entidades com o fito de avaliar a qualidade do atendimento.

Os artigos apresentados no I, II, III e IV Encontro Nacional do Serviço Social no Ministério Público (ENSSMP), realizados de 2006 a 2012, bianualmente, são aqui considerados expressão das demandas trabalhadas pelos profissionais neste espaço sócio-ocupacional. Foram elaborados, no período, setenta artigos, entre os quais o tema com maior destaque é a direção social do Serviço Social no Ministério Público, com 34,27\% (24) das produções, sendo que muitos dos textos realizam a apresentação das experiências profissionais, enfocando os avanços e dificuldades na aproximação daquilo que consideram o direcionamento almejado pela categoria na instituição. Em seguida, tem-se a temática da fiscalização de entidades de atendimento e políticas públicas que figura com 10\% (7) do todo, o que encontra rela- 
ção com a atuação no âmbito do direito coletivo e com a previsão em diversas legislações de atribuições do Ministério Público na fiscalização das entidades de atendimento e da defesa de direitos de modo geral, materializada por meio das políticas públicas.

É interessante apontar, igualmente, a significância das produções em torno dos novos sujeitos de direitos, ou seja, segmentos como o idoso, a pessoa com deficiência, a mulher, que, juntos, contam com $25,71 \%$ (18) das produções. $\mathrm{O}$ infantojuvenil, por sua vez, embora não apareça como tema central, consta em muitos artigos como pano de fundo, em discussões cujo foco está deslocado para outros temas: a estratégia metodológica do trabalho em rede ou do estudo de caso, a fiscalização de entidades, a garantia do direito à convivência familiar, o disque 100 ou o ato infracional praticado por adolescente. $\mathrm{O}$ mesmo ocorre, em menor medida, com o segmento idoso e pessoa com deficiência, quando o tema é a interdição.

A amplitude das demandas identificadas permite compreendê-las como requisições que estão impregnadas de visões de mundo, de concepções e de posições políticas. Por exemplo, o primeiro grupo de demandas — as de cunho individual — encontra relação com a tradição de atuação do Serviço Social no Poder Judiciário, na elaboração de estudos sociais relativos a situações familiares onde há violação de direitos ou litígios. Certamente, essa forma histórica de inserção marca o ingresso do Serviço Social no Ministério Público, pois seus membros tinham como referência essa atuação, demandando-a em um primeiro momento. A atenção a demandas de cunho individual é atravessada por contradições que, encharcadas da vivência no mundo jurídico, assumem determinadas características, como a tendência a serem desenraizadas de suas bases econômicas e sociais, para serem abstraídas e respondidas de modo fragmentário. Nesse sentido, Aguinsky (2003), pesquisadora sobre a inserção do Serviço Social no Poder Judiciário, explicita tais características:

A moralidade implicada no ethos da sociedade liberal providencia uma análise e tratamento da questão social delimitada na ótica de problemas isolados, fragmentando a vida social que deixa de ser apreendida como totalidade, mas, antes, como um agregado de partes autônomas. Essa moralidade, ao mesmo tempo em que pode ser ponderada como instrumento ideológico de ocultamento das bases materiais e estruturais da questão social, dimensiona seu enfrentamento (da questão social) na perspectiva da internalização social de normas e deveres que se constituem de modo despolitizado - como que na fundamentação de uma expectativa social prevalente, na direção de comportamentos desenraizados politicamente frente às expressões de desigualdade 
na sociedade que, em verdade, traduzem demandas de direitos sociopolíticos, que assim não são consideradas.

Aos argumentos expostos por Aguinsky (2003) quanto à abordagem da questão social nessa dimensão, cumpre acrescentar que o Ministério Público é instituição distinta do Poder Judiciário, pois suas atribuições devem assumir a direção da garantia dos direitos humanos no contexto judicial e extrajudicial. Assim, a referência do Serviço Social Judiciário pode conduzir a uma ênfase da atuação profissional na esfera individual, assumindo facetas fragmentárias, pontuais, menos abrangentes e descoladas da missão da instituição ministerial. Pode, também, constituir-se em espaço de garantia de direitos a sujeitos que os tiveram violados ou sonegados. Por seu turno, o Serviço Social tem o potencial de descortinar na instituição um leque de intervenções voltadas para a garantia de direitos de coletividades, em caráter mais abrangente e continuado, quando sua intervenção se volta ao fomento de políticas públicas de Estado.

Os artigos apresentados pelos assistentes sociais nos encontros do Serviço Social no Ministério Público retratam experiências de intervenção no âmbito das coletividades, na fiscalização de entidades, no fomento de políticas públicas e, até mesmo, na reflexão em torno de intervenções relativas às avaliações sociais, de modo que o tema das políticas públicas se revela permanente. A tendência predominante é a do debate em torno das políticas públicas da proteção social de modo genérico, enfocando o papel do Estado na garantia dos direitos humanos, perfazendo $58,57 \%$ (41), sendo que apenas 18,57\% (13) não abordavam o tema das políticas públicas. Quanto à discussão específica das políticas, emergem dos materiais a saúde, com 7,14\% (5), a assistência social, com 5,72\% (4), e a educação, com 4,28\% (3), dando-se maior relevo à primeira, em torno das temáticas da saúde do trabalhador, da saúde em geral e da saúde mental.

Neste contexto de leitura das políticas públicas da proteção social, as duas dimensões - individual e coletiva - chegam a ser dicotomizadas, contrapostas nos textos analisados, muito embora, como já referido, a preocupação com a contextualização e a compreensão dos determinantes da vida social acompanhe o conjunto das análises, mesmo as que se referem ao âmbito individual. Não se trata de optar por uma dimensão de intervenção ou outra, mas de percebê-las no movimento contraditório do real, conectando a particularidade e a universalidade, isso dentro de um processo de planejamento da atividade profissional que não permita a captura pela alienação do cotidiano. 
Portanto, a questão das demandas sociais para o Serviço Social não é algo percebido na visibilidade aparente dos problemas e necessidades sociais, mas é um processo que requer um aprofundamento analítico na investigação da realidade social em suas várias facetas, para que possam ser devidamente operadas as mediações teórico-políticas [...]. (Serra, 2000, p. 165)

No que diz respeito à direção social da atuação do Serviço Social no Ministério Público, o I ENSSMP, promotor da primeira síntese coletiva sobre o tema, concluiu ser

a atuação no campo da assessoria, subsidiando e propondo ao Ministério Público no campo das políticas públicas e na garantia de direitos nas diversas áreas, buscando coletivizar os casos individuais [...] fomentar a materialização dos direitos sociais em políticas públicas. (Rio Grande do Sul, 2006, p. 26)

Nesse contexto, o objeto da intervenção do Serviço Social, compreendido genericamente como a questão social, vai adquirir contornos específicos neste espaço sócio-ocupacional. Como assinala Baptista (2002), a delimitação do objeto da intervenção requer sucessivas aproximações, em um processo permanente de reconstrução.

A direção social e o processo de delimitação do objeto confluem para o projeto ético-político-profissional. Evidencia-se, nos materiais analisados, a percepção de que há uma profunda relação entre a missão institucional do Ministério Público, conferida na Constituição Federal de 1988, e o projeto ético-político do Serviço Social, especialmente quanto à defesa da democracia e dos direitos humanos, conforme segue:

[...] antes de representar uma resposta técnico-operativa às solicitações institucionais, construídas majoritariamente pela ótica dos demandatários (promotores de Justiça), visa atender originalmente às demandas dos usuários do Serviço Social, tendo como fio condutor o referencial ético-político construído historicamente pela profissão, e expresso no atual Código de Ética Profissional. Este traz em seu bojo princípios que reforçam a materialização de uma conduta aliada não apenas a um projeto profissional, mas, sobretudo, a um projeto societário anticapitalista e antiburguês. Dentre tais princípios, frisamos a defesa do aprofundamento da democracia, o posicionamento em favor da equidade e da justiça social, a ampliação e consolidação da cidadania e o compromisso com a qualidade dos serviços prestados. (Silva e Silva, 2006, p. 4) 
Ramos (2002), docente em Serviço Social, discutindo o projeto ético-político da profissão e suas conexões com um projeto societário, delimita melhor os limites e potencialidades do projeto profissional:

Do meu ponto de vista, a denominação ético-político, presente no projeto profissional, não se fundamenta em uma visão mecanicista, como se o projeto profissional tivesse condições para ocupar o lugar de um projeto societário. O termo projeto ético-político profissional expressa a existência, neste projeto coletivo, da nítida dimensão ética, na medida em que convoca os profissionais de Serviço Social para refletir sobre os valores e desvalores que orientam suas ações. Ao fazer isto, este projeto vincula-se à defesa de determinados valores e princípios éticos identificados com a busca da emancipação humana. $\mathrm{O}$ termo projeto ético-político apresenta, ainda, uma clara dimensão política, que se constrói no bojo das relações sociais, no movimento das classes sociais, considerando as opções políticas subjetivas e a construção de estratégias no campo democrático-popular, estabelecendo, no entanto, um conjunto de mediações no ambiente profissional. (Ramos, 2002, p. 92)

Contudo, a assertiva de Silva e Silva (2006) contém outro elemento importante para a análise, além da afirmação do projeto ético-político profissional. Ela retrata certa contraposição entre as demandas instituintes e as dos usuários. Aliás, essa disjunção é apresentada por autores do Serviço Social, como Serra (2000), para a qual, no caso da profissão, há uma separação entre quem demanda e quem recebe diretamente os serviços, sendo as demandas compreendidas como requisições técnico-operativas. Tal posicionamento permite introduzir um aspecto essencial para a condução da intervenção profissional na instituição, ou seja, de que as demandas institucionais são o ponto de partida do delineamento da intervenção profissional, como menciona Baptista (2002, p. 32):

Na prática, a (re)construção do objeto da ação profissional é um processo que envolve operacionalização das demandas institucionais, das pressões dos usuários e das decisões profissionais. Uma vez que a intervenção e o planejamento da ação do profissional se realizam primordialmente nas instituições, é a demanda institucional o ponto de partida e o ponto de referência para essa construção e para o planejamento da intervenção. Isso não implica a redução da decisão e da ação aos limites institucionais, mas o reconhecimento de que essa demanda pode potencializar a abertura de novos espaços para enfrentamento concreto da questão a ser trabalhada. 
Todavia, Iamamoto (2008), em recente obra que discute a profissão e seus rumos frente ao capitalismo contemporâneo, discorre sobre o trânsito entre a análise da profissão e o seu efetivo exercício, ou seja, a autora parte da condição de trabalho assalariado alienado e pontua seus condicionantes à efetivação da direção social que se projeta. Sustenta ela:

Esta condição sintetiza tensões entre o direcionamento que o assistente social pretende imprimir ao seu trabalho concreto - afirmando sua dimensão teleológica e criadora - condizente com um projeto profissional coletivo e historicamente fundado; e os constrangimentos inerentes ao trabalho alienado que se repõem na forma assalariada do exercício profissional. (Iamamoto, 2008, p. 214)

Para essa autora, o significado social do trabalho do assistente social depende das condições e relações estabelecidas com seus contratantes, no caso, do Ministério Público, agentes do Estado, administradores da instituição. Os empregadores determinam as necessidades sociais a serem atendidas, a matéria sobre a qual incide o trabalho (recortes das expressões da questão social), as suas condições (intensidade, jornada, salário, controle do trabalho, produtividade e metas) e efeitos na reprodução das relações sociais (Iamamoto, 2008).

No que tange às condições de trabalho, evidencia-se um empenho da instituição na disponibilização de recursos materiais para o exercício profissional (Dortas, 2006). Apesar disso, as resoluções dos encontros nacionais (Rio Grande do Sul, 2006; Distrito Federal, 2008) mencionam a necessidade de adequar as condições de trabalho às normativas profissionais vigentes (Resolução CFESS n. 493/2006, de 21/8/2006), assim como fazem referência à precarização do trabalho técnico com contratações terceirizadas em alguns estados, criando dois quadros, um concursado e outro terceirizado (Grupo Focal, P1). Nesse sentido, as agendas de lutas, são: criação do cargo de assistente social onde não há; criação de adicional de periculosidade devido à realização de visitas domiciliares em locais perigosos; nomeação de concursados; abertura de concursos públicos; defesa do ingresso por meio exclusivo do concurso público; fortalecimento do movimento de redução da carga horária, conforme Projeto de Lei n. 1.897/2007. Em muitos Estados, o número insuficiente de profissionais já vem resultando na demora do atendimento às demandas, assim como a excessiva demanda individual dificulta a atenção às matérias coletivas (Grupo Focal, P7).

As condições de trabalho não estão apartadas da direção social que a intervenção venha a adquirir, pois o desenvolvimento da profissão guarda relação com 
a (re)valorização da sua função social, perpassando aspectos concretos, como a criação de novos postos de trabalho, constituição de novas demandas, diante de novas necessidades sociais e pela valorização salarial. Todavia, todos esses aspectos são determinados historicamente, sendo permeados pelos processos sociais da realidade e pelos movimentos da própria categoria profissional (Serra, 2000).

É justamente nesse espaço tenso e contraditório que se situa o protagonismo dos assistentes sociais. A atuação do profissional tem relativa autonomia, pois as condições dadas pelo empregador condicionam os resultados do trabalho e, com isso, o projeto profissional, como mencionado a seguir:

[...] a possibilidade de imprimir uma direção social ao exercício profissional do assistente social - moldando o seu conteúdo e o modo de operá-lo — decorre da relativa autonomia de que ele dispõe, resguardada pela legislação profissional e passível de reclamação judicial. A efetivação dessa autonomia é dependente da correlação de forças econômica, política e cultural em nível societário e se expressa, de forma particular, nos distintos espaços ocupacionais, que envolvem relações com sujeitos sociais determinados: a instituição estatal (Poder Executivo e Ministério Público, Judiciário e Legislativo); as empresas capitalistas; as organizações político-sindicais; as organizações privadas não lucrativas e as instâncias públicas de controle democrático (Conselhos de Políticas e de Direitos, conferências, fóruns e ouvidorias), que sofrem profundas metamorfoses sociais em tempo de capital fetiche. (Iamamoto, 2008, p. 220)

Dessa forma, foram identificadas nos textos analisados estratégias intracategorias e gerais. As estratégias intracategorias assumem a faceta articuladora do grupo profissional, no sentido de forjar a direção social da intervenção, fortalecer a identidade, buscar legitimação e reconhecimento, obter as condições necessárias ao seu trabalho e o aprimoramento profissional. As estratégias intracategorias são aquelas construídas a partir do coletivo - categoria profissional no Ministério Público.

As estratégias intracategorias denotam a percepção de que isoladamente os profissionais perdem força nas suas demandas e proposições de trabalho, sendo a aliança entre os pares um modo de dar visibilidade ao conjunto dos atores profissionais e buscar alguma condição de protagonismo. Ramos (2002), ao discutir a construção de projetos coletivos, tendo por base a produção de Agnes Heller, Karl Marx e Gramsci, nomeia três elementos que contribuem para a viabilização/projeção de projetos coletivos: a necessidade, a consciência e a vontade. 
As necessidades são construídas social e historicamente com mediação da cultura. A busca por suprir as necessidades leva os indivíduos a se agruparem coletivamente com vistas à construção de um projeto societário que os satisfaça. A formação da consciência humano-genérica se dá como mediação para a ação coletiva. Os grupos sociais, no desenvolvimento de suas lutas, consolidam alianças voltadas para a superação do plano corporativo, na direção do universal e da unidade que, em busca de uma nova hegemonia, materializa-se em propostas políticas e valores éticos. A vontade, por sua vez, distingue-se do mero desejo, pois é permeada por relações sociais e tensões. Além disso, a realização da vontade coletiva carece de previsão, de concepção de mundo, de querer e de paixão (Ramos, 2002).

No que diz respeito às estratégias gerais, ou seja, aquelas relativas à relação profissional-instituição, que vêm sendo construídas pelos assistentes sociais do Ministério Público, no cotidiano de implantação e implementação de seu trabalho, especialmente o documento final do I Encontro Nacional do Serviço Social no Ministério Público foi profícuo quanto ao seu delineamento, pautando:

[...] definir e divulgar o papel do profissional de Serviço Social na instituição; distinguir atribuições periciais e de assessoramento técnico (incluindo a produção diferenciada de documentos), definindo o papel do assistente social no Ministério Público como de assessoramento técnico; obter o reconhecimento das atribuições e possibilidades do Serviço Social; atuar na perspectiva da interdisciplinaridade e intersetorialidade; dar maior visibilidade ao projeto ético-político do SS no cotidiano profissional; apresentar-se como uma profissão habilitada a atuar no campo das políticas públicas (fiscalização, fomento, acompanhamento, controle e avaliação), não se limitando aos casos individuais, de acordo com as atribuições do MP; deixar claro que o espaço profissional do SS do MP não é campo de execução de políticas públicas; legitimar o espaço de trabalho; pensar nas demandas do interior dos estados; criar espaços de diálogo entre os integrantes do Ministério Público (membros e servidores). (Rio Grande do Sul, 2006, p. 26)

Como se pode observar, as estratégias construídas pelos assistentes sociais buscam alcançar o reconhecimento e a delimitação de atribuições, convergindo para a sua visibilidade como uma área profissional capaz de contribuir na tarefa institucional de defesa e garantia do direito à proteção social.

A coletivização das demandas individuais, buscando percebê-las como direitos universais, é uma das estratégias centrais do Serviço Social na instituição 
(Grupo Focal, P8). Essa estratégia encontra consonância com as reflexões de Iamamoto (2008) quanto ao desafio para o assistente social, no seu trabalho cotidiano, de desentranhar das situações singulares de indivíduos, famílias, grupos e segmentos, atravessadas por determinações de classe, as suas dimensões universais. Com isso, propõe transitar da esfera privada para a cena pública onde se processa a luta por direitos.

Todavia, no espaço do grupo focal, é pontuada a complexidade de transformar demandas individuais em coletivas, pois exige um processo de mudança na instituição como um todo e do demandante de determinada ação, ou seja, os condicionantes institucionais estão sempre presentes:

[...] porque antes de o promotor aceitar a nossa proposta de coletivizar aquilo que aparece individualmente, ele tem que se sentir incomodado pela questão social e ele não se sente, porque ele nunca visitou uma favela [...]. Ele vem naquela trajetória de classe, e aí chega lá o instituído que está bem colocado porque quem não tem projeto assume o projeto em vigor e o projeto em vigor das instituições é um projeto burguês, todas as instituições estão atravessadas por ele. (Grupo Focal, P1)

As reflexões de Aguinsky (2003) acerca do Poder Judiciário podem auxiliar a compreender as lógicas que operam no Sistema de Justiça e que dificultam a ruptura com o lugar tradicional deste. Nesse diapasão, o direito apresenta-se como um dos instrumentos utilizados pelo Estado para gerir conflitos presentes nas relações sociais, na ótica de comportamentos socialmente admissíveis e desejáveis, que não coloquem em risco os interesses do capital.

Assim, um estudo social construído a partir da ótica da garantia de direitos foge ao lugar-comum do enquadramento das relações sociais. Ele traz novos prismas interpretativos para as situações individuais que as conectam ao universal, às determinações sociais, políticas, econômicas e culturais e, por isso, causa estranheza. Contraditoriamente, a própria missão contemporânea do Ministério Público o conduz ao encontro de visões mais abrangentes e contextualizadoras. Nessa concepção, talvez alguns dos agentes ministeriais ainda não estejam plenamente preparados para fazer a mediação particular-universal, para transpor o individual ao coletivo, para perceber a situação individual de modo menos criminalizante ou culpabilizador.

Transparece, nos dados coletados, aquilo que as pesquisadoras em Serviço Social Martinelli e Koumrouyan (1994) chamaram de "indicadores coletivamente 
construídos", representados por dois eixos: a efetividade das ações e o seu alcance social. O primeiro, relativo à força política das ações desenvolvidas no que tange à transformação social da realidade; o segundo, referente ao impacto junto à população. Essa parece ser a questão que se coloca nos textos produzidos pelos assistentes sociais do Ministério Público e das expressões verbais quanto ao desenvolvimento de ações que impactem a realidade social na direção da garantia dos direitos humanos.

\section{0 direito difuso e coletivo como eixo da atuação do Serviç̧o Social}

Para que se possa incidir institucionalmente no direcionamento do trabalho profissional, é relevante a perspectiva interdisciplinar, a qual figura entre as estratégias mencionadas pelos profissionais, embora sem maior densidade na produção. É curiosa a baixa relevância da temática, pois a interdisciplinaridade remete ao diálogo com o direito, área do conhecimento central na instituição, pois de formação de seus membros. A esse propósito, Aguinsky (2003, p. 90) pontua que "de nada adiantaria a atuação do assistente social, alcançando com sua competência particular, o que a ótica do Direito não alcança se, ao final, não fosse esta competência traduzida em outra - a da linguagem institucional, a linguagem do Direito".

Assim, coloca-se, ao mesmo tempo, como possibilidade e desafio a constituição de processos dialógicos com os membros do Ministério Público. É por meio das decisões tomadas por eles que as indicações do Serviço Social terão incidência intrainstitucional e na atuação da instituição em face dos distintos atores da esfera pública, implicados com a efetivação ou não dos direitos humanos.

A perspectiva interdisciplinar articula-se à dimensão do planejamento. Sousa (2008) realiza uma síntese das estratégias que devem ser implementadas pelo Serviço Social no Ministério Público, articulando diferentes dimensões:

[...] o Serviço Social necessita apropriar-se de seu lugar, impor seus limites, realizar pesquisas, estudos e planejar melhor sua atuação para propor ações que somadas à missão do Ministério Público contribuam efetivamente para a construção de uma nova ordem societária. (Sousa, 2008, p. 7) 
A questão que se coloca é a necessidade de superar o cotidiano e envidar esforços no sentido de planejar e refletir acerca dele, sob pena de a intervenção profissional submergir às demandas cotidianas que, tratadas de modo pontual, muitas vezes se tornam empobrecedoras das possibilidades de contribuição do Serviço Social no que diz respeito à garantia dos direitos humanos. Assim, o planejamento

vem em oposição àquela em que as decisões são tomadas ao sabor das necessidades emergentes, quando as atividades são informadas e decididas em razão do desenvolvimento natural de uma situação, sem uma consciência clara de sua importância no espaço mais amplo, no qual se insere. (Baptista, 2002, p. 79)

Nesse viés, Baptista (2002), a partir de suas diversas produções na área do planejamento, propõe dois critérios básicos para a eleição de prioridades de intervenção: a relevância e a viabilidade. A relevância diz respeito à percepção sobre o impacto da ação, em que a questão em análise deve ser vista no seu conjunto, verificando a importância de cada variável com relação ao problema, suas determinações, interação entre diferentes aspectos, consequências e processos emergentes. Já a viabilidade relaciona-se à avaliação da influência do planejador sobre os problemas objeto do planejamento. Ela exige a leitura da governabilidade de quem planeja sobre o espectro da ação vislumbrada.

Avançando um pouco mais, a autora mencionada traz contribuições importantes para se pensar o processo de planejamento do Serviço Social no Ministério Público. Propõe, para o estudo da viabilidade das prioridades, a análise dos seguintes aspectos:

[...] o âmbito institucional, suas funções e responsabilidades; as possibilidades concretas de intervenção em termos financeiros, de pessoal, de conhecimentos acumulados, de técnicas e de prazos; a coerência com a política definida em outros níveis; a compatibilidade com a situação social, econômica e política vigente; a oportunidade política para agir sobre a causa identificada; o índice de possibilidade de aceitação, por parte da população usuária. (Baptista, 2002, p. 76)

Tais contribuições são pertinentes, uma vez que oferecem elementos concretos para o processo de planejamento. A direção social que se pretende imprimir à intervenção do Serviço Social na instituição não se faz a partir do voluntarismo ou do mero pensamento desejoso. Ela carece de processos de formulação que façam 
uma apropriada análise da conjuntura institucional, das relações e dos projetos políticos em disputa no espectro dos direitos humanos, que mapeie as forças apoiadoras e opositoras dos processos de garantia de direitos e, sobretudo, indique a composição das alianças necessárias, pois o assistente social isoladamente é incapaz de conduzir e incidir em processos emancipatórios, visto que se constituem em tarefa coletiva.

No que tange às possibilidades de contribuição, os materiais estudados convergem para o eixo central da contribuição quanto ao acesso da população aos seus direitos, no cenário da atuação extrajudicial. A atuação no âmbito coletivo é percebida como privilegiada pelos profissionais, com base no entendimento de que sua participação em matérias coletivas, que são ou precisam ser objeto da intervenção da instituição, deve ocorrer na defesa, garantia e ampliação de direitos.

Foram apontadas, por membro da instituição, contribuições relativas à sensibilidade para a identificação de necessidades sociais e quanto ao diálogo com diferentes segmentos, sendo emblemática dessas possibilidades a seguinte assertiva:

Tem contribuído de forma consistente na aproximação das pessoas e dos segmentos sociais em situação de vulnerabilidade em relação à instituição, no planejamento e na execução de planos e projetos institucionais voltados à garantia dos direitos constitucionais, na abertura de diálogos importantes na busca de soluções para as questões apresentadas aos órgãos ministeriais e nos procedimentos voltados ao cumprimento das funções atribuídas ao Ministério Público. (Questionário, 2)

Dentre as possibilidades de contribuição, destaca-se, ainda, a de favorecer o diálogo com a sociedade civil, especialmente os movimentos sociais organizados, com os quais o assistente social poderá atuar como "ponte entre o promotor e a sociedade" (Grupo Focal, P8). Na mesma perspectiva, outro profissional menciona, à luz de seu espaço específico de intervenção, que a atuação do Serviço Social na interlocução com os movimentos sociais já está sendo incorporada ao processo de trabalho da instituição. É proposta, também, a atuação junto ao controle social das políticas públicas, em comissões temáticas dos conselhos (Metzner e Pollis, 2006). As deliberações do I Encontro Nacional do Serviço Social no Ministério Público (Rio Grande do Sul, 2006, p. 29) da mesma forma apontavam para esse entendimento: "promover, fomentar e fortalecer ações de articulação entre os atores da rede social; - fortalecer o controle social em articulação com os movimentos sociais, com vistas ao enfrentamento das questões coletivas". 
O eixo da intervenção, que se volta para o fortalecimento do controle social e dos movimentos sociais, encontra sentido na perspectiva gramsciana no que tange à construção da contra-hegemonia. Esta diz respeito à possibilidade de superação da condição de subalternidade pelos grupos dominados, incidindo na construção de novos modos de pensar, que se refletem na concepção de mundo, a partir da reflexão crítica que supera o senso comum (Simionatto, 2009).

A atuação por meio de redes sociais, as mediações com vários órgãos e atores sociais e a gestão participativa (relação direita com os usuários, socialização de conhecimentos, interdisciplinaridade, fortalecimento dos usuários) são eixos metodológicos percebidos como possíveis no exercício profissional no Ministério Público (Metzner e Pollis, 2006). Foram mencionados, por assistente social participante de grupo focal, além dos já mencionados, mecanismos concretos, com relação aos quais o Serviço Social vem contribuindo no sentido da democratização das relações entre o Ministério Público e a sociedade, bem como quanto à construção de movimentos contra-hegemônicos, como a realização das audiências públicas nas comunidades para captação de demandas de proteção social, ao lado da contribuição na mediação com os movimentos sociais e com os mecanismos de controle social (Grupo Focal, P2). Tais contribuições requerem, sob o ponto de vista de participante do grupo focal (P2), o desenvolvimento de metodologias que permitam a articulação com os movimentos sociais e conselhos de direitos, bem como uma ampliação da participação da comunidade.

Além dos eixos já mencionados, o do assessoramento técnico quanto à exigibilidade de políticas públicas (fiscalização, fomento, acompanhamento e avaliação) mostra-se como uma possibilidade de compor as atribuições do Serviço Social, de modo alinhado com a missão do Ministério Público. Esse âmbito de assessoria vem revelando-se mais eficaz e de grande importância para a população que vivencia o não acesso a direitos, além de ter um impacto social maior, haja vista abranger conjuntos populacionais expressivos e ter repercussões transgeracionais.

Em diversos textos produzidos por assistentes sociais, as políticas públicas são destacadas como forma de efetivar os objetivos traçados na Constituição Federal, competindo ao Ministério Público utilizar todos os meios jurídicos disponíveis para tê-las implementadas. "[...] evidencia-se a importância e urgência da ação ministerial no campo das políticas públicas, quanto ao seu fomento e qualificação. Esse tipo de intervenção pode resultar em uma futura redução das demandas individuais nas diversas áreas nas quais o Ministério Público atua" (Rey, Perin e Tejadas, 2008, p. 5). A mesma ideia é compartilhada por membros do Ministério Público: 
Conclui-se então que as políticas públicas são instrumentos imprescindíveis para que os objetivos traçados pela Constituição de 1988 sejam efetivamente cumpridos, cabendo ao Ministério Público utilizar instrumentos jurídicos dos quais dispõe para vê-las implementadas, garantindo, com isso, o desenvolvimento e a democracia, pressupostos de uma sociedade livre, justa e igualitária. (Ramos, 2001, p. 26-27)

A esse propósito, Gravronski (2006), incursionando o tema, destaca diversos aspectos que envolvem a atuação do promotor de justiça na tutela de direitos coletivos. Menciona o autor as peculiaridades extrajudiciais do assunto, a necessária criatividade do membro da instituição, a articulação com a sociedade civil e com órgãos públicos afins, a assessoria de servidores especializados, além do domínio de instrumentos como o inquérito civil ou o procedimento administrativo, o compromisso de ajustamento de conduta, a recomendação e a ação civil pública.

Nesse contexto, a fiscalização de entidades de atendimento visa avaliar a qualidade dos serviços que estão sendo oferecidos à população, tendo por base o marco legal vigente, pesquisas e estudos sobre as políticas públicas em análise. $\mathrm{O}$ conhecimento na área do Serviço Social situa o assistente social como profissional especializado, habilitado para a realização de avaliações de programas de acolhimento institucional para crianças e adolescentes, de unidades de internação, de instituições de longa permanência para idosos, de escolas (infantis, ensino fundamental e médio), de instituições especializadas no atendimento a pessoas com deficiência e a dependentes químicos, entre outras. A atribuição no campo da fiscalização de entidades requer o uso de múltiplos instrumentos, como: estudo da temática, estruturação de roteiros específicos, visita institucional, entrevistas com dirigentes, técnicos, usuários dos serviços e, ainda, observação e coleta de imagens.

É importante destacar que, de modo geral, a atribuição de fiscalização não é exclusiva do Ministério Público, mas também de competência de outros órgãos do Sistema de Garantia de Direitos, inclusive conselhos de direitos. Nesse sentido, impõe-se a necessidade de processos de trabalho conjuntos, o que, sem dúvida, aumenta as possibilidades de influência quanto à qualificação das políticas públicas, o compartilhamento de saberes e a corresponsabilização.

A avaliação de projetos elou de políticas públicas, por sua vez, visa analisar a pertinência, a adequação ao marco legal e ao acúmulo de conhecimentos acerca das políticas públicas, por meio da análise de projetos apresentados pelo Poder Público ou organizações não governamentais, envolvendo aspectos metodológicos, de infraestrutura e de recursos humanos. São instrumentos para a avaliação de 
projetos e/ou políticas públicas: estudo da temática; estruturação de roteiros específicos; possibilidade de coleta de campo, com visita institucional, entrevista com gestores, técnicos, usuários dos serviços, observação, imagens e/ou análise de documentos, como planos, projetos e relatórios. Nesse caso, há a análise da política pública como um todo, com seus múltiplos serviços, às vezes demandando vistorias a diversos equipamentos.

Ainda no rol de atribuições no âmbito das matérias de direito difuso e coletivo, o Serviço Social pode contribuir com a realização de estudos e pesquisas, relacionados a temas de interesse das Promotorias de Justiça e a centros de apoio operacionais, ou decorrentes da reiteração de determinadas demandas e da observação de tendências quanto a lacunas na execução de determinadas políticas e/ou à necessidade de implementação de mudanças paradigmáticas. Nesse caso, além do conjunto de conhecimentos oriundos da formação profissional, pode ser necessária a consulta a especialistas nas áreas em análise, bem como o estudo de legislações e a consulta a pesquisas das ciências sociais.

No processo de inserção do Serviço Social no Ministério Público, é fundamental que se atue no sentido de incidir nas atribuições da profissão, aproximando-as da intervenção no âmbito do direito difuso e coletivo, visto o potencial destes na ampliação e garantia dos direitos humanos. Nessa contextura, o desafio está em constituir processos de trabalho planejados que partam da interpretação crítica da realidade, avaliando estratégias, alianças e proposições viáveis que considerem

o potencial de que dispõe para impulsionar a luta por direitos e a democracia em todos os poros da vida social; potencial esse derivado das contradições presentes nas relações sociais, do peso político dos interesses em jogo e do posicionamento teórico-prático dos sujeitos profissionais ante os projetos societários. (Iamamotto, 2008, p. 417)

Para tanto, a percepção dicotomizada entre condicionantes e possibilidades conduz a vieses ora fatalistas, ora messiânicos. O primeiro percebe a lógica do capital como intransponível, não identificando possibilidades de dar direção às atividades, subsumindo aos comandos instituintes. O segundo subestima os determinantes e superestima a vontade do coletivo profissional (Iamamotto, 2008). A busca por caminhos coletivos pelo Serviço Social tem a potência de oferecer a densidade política necessária à categoria para incidir na definição de suas atribuições, pautada pela leitura da conjuntura institucional e das alianças capazes de fortalecer 
a direção social do Ministério Público em torno da defesa da democracia e dos direitos humanos.

\section{Considerações finais}

É no contexto de reordenamento jurídico e institucional do Ministério Público que o Serviço Social se insere, sendo que, desde os primeiros momentos, vem buscando constituir uma identidade e direção social hegemônica. No diferenciado território nacional, a profissão trilha um caminho repleto de ambiguidades e contradições, em que a direção social de sua intervenção, anunciada no projeto ético-político-profissional, compartilha de propósitos convergentes com a missão da instituição, conferida pela Constituição brasileira. Contudo, a materialização de projetos que se interconectam dialeticamente oscila entre o devir e a concretude, entre as possibilidades e os limites. Nesse diapasão, o Serviço Social é uma profissão das ciências sociais aplicadas, capacitada para atuar na transversalidade das políticas públicas, compreendendo-as como processo histórico de concessão-conquista, por isso imersas em relações entre diferentes atores da esfera pública.

Nessa orientação, o Serviço Social pode e tem contribuído no diálogo com os movimentos sociais, com os conselhos de direitos, perseguindo o propósito de que o fomento de políticas públicas se faça de modo articulado às demais instâncias que atuam na defesa de direitos. Ao mesmo tempo, no âmbito da fiscalização da qualidade das políticas públicas, tem contribuído para oferecer subsídios quanto ao planejamento desses processos, calcado nos acúmulos técnicos disponíveis. Considerando que o projeto de consolidação da democracia é coletivo e não se restringe aos muros do Ministério Público, o Serviço Social vem se constituindo como uma área profissional que tem contribuições importantes a oferecer em direção a um ideário emancipatório, no qual os direitos humanos sejam realidade.

Recebido em 14/5/2013 - Aprovado em 10/6/2013 


\section{Referências bibliográficas}

AGUINSKY, Beatriz Gershenson. Eticidades discursivas do serviço social no campo jurídico: gestos de leitura do cotidiano no claro-escuro da legalidade da moral. 2003. 290f. Tese (Doutorado em Serviço Social) - Pontifícia Universidade Católica do Rio Grande do Sul, Faculdade de Serviço Social, Porto Alegre, 2003.

BAPTISTA, Myriam Veras. Planejamento social: intencionalidade e instrumentação. Lisboa: Veras, 2002.

DORTAS, Mercedes Cabirta. O Serviço Social no Ministério Público de Sergipe. In: ENCONTRO NACIONAL DO SERVIÇO SOCIAL NO MINISTÉRIO PÚBLICO, 1., Anais... Porto Alegre, Ministério Público do Rio Grande do Sul, 2006. [CD-ROM.]

GRAVRONSKI, Alexandre Amaral. Tutela coletiva: visão geral e atuação extrajudicial. Brasília: Ministério Público Federal, 2006.

IAMAMOTO, Marilda. Serviço Social em tempo de capital fetiche: capital financeiro, trabalho e questão social. São Paulo: Cortez, 2008.

MAIA NETO, Cândido Furtado. O promotor de justiça e os direitos humanos: acusação com racionalidade e legalidade por um Ministério Público democrático. Curitiba: Juruá, 1999.

MARTINELLI, Maria Lúcia; KOUMROUYAN, Elza. Um novo olhar para a questão dos instrumentais técnico-operativos em Serviço Social. Serviço Social \& Sociedade, São Paulo, ano XV, n. 45, p. 137-141, ago. 1994.

MAZZILLI, Hugo Nigro. O acesso à justiça e o Ministério Público. São Paulo: Saraiva, 1998.

METZNER, Clarice; POLLIS, Rosilene de Fátima. O Ministério Público pensado e vivido. In: ENCONTRO NACIONAL DO SERVIÇO SOCIAL NO MINISTÉRIO PÚBLICO, 1., Anais... Porto Alegre, Ministério Público do Rio Grande do Sul, 2006. [CD-ROM.]

MINISTÉRIO PÚBLICO DO DISTRITO FEDERAL E TERRITÓRIOS. In: ENCONTRO NACIONAL DO SERVIÇO SOCIAL NO MINISTÉRIO PÚBLICO, 2., Relatório Final, Brasília: Ministério Público do Distrito Federal e Territórios, 2008.

MINISTÉRIO PÚBLICO DO RIO GRANDE DO SUL. Relatório do I Encontro Nacional do Serviço Social no Ministério Público. Porto Alegre: Ministério Público do Rio Grande do Sul, 2006.

NOGUEIRA, Marco Aurélio. Um Estado para a sociedade civil: temas éticos e políticos da gestão democrática. São Paulo: Cortez, 2004.

PORTO, Pedro Rui da Fontoura. Direitos fundamentais sociais: considerações acerca da legitimidade política e processual do Ministério Público e do sistema de justiça para sua tutela. Porto Alegre: Livraria do Advogado, 2006. 
RAMOS, Paulo Roberto Barbosa. O Ministério Público e a efetividade das políticas públicas. In: CONGRESSO NACIONAL DO MINISTÉRIO PÚBLICO, MINISTÉRIO PÚBLICO E CIDADANIA PLENA, 14., Livro de teses... Recife, Associação do Ministério Público de Pernambuco, v. 1, t. 1, 2001.

RAMOS, Sâmya Rodrigues. A construção de projetos coletivos: refletindo aspectos do projeto profissional do Serviço Social. Temporalis, Brasília, ano 3, n. 5, p. 81-93, jan./jun. 2002.

REY, Beatriz Fortes; PERIN, Silvana Dóris; TEJADAS, Silvia da Silva. Análise da intervenção do Serviço Social no Ministério Público do RGS. In: ENCONTRO NACIONAL DO SERVIÇO SOCIAL NO MINISTÉRIO PÚBLICO, 2., Relatório final. Brasília, Ministério Público do Distrito Federal e Territórios, 2008.

RITT, Eduardo. O Ministério Público como instrumento de democracia e garantia constitucional. Porto Alegre: Livraria do Advogado, 2002.

ROJO, Raul Enrique (Org.). Sociedade e direito no Quebec e no Brasil. Porto Alegre: UFRGS, 2003.

SERRA, Rose M. S. Crise de materialidade no Serviço Social: repercussões no mercado profissional. São Paulo: Cortez, 2000.

SILVA, Anália dos Santos; SILVA, Márcia Nogueira da. O Serviço Social no Ministério Público do estado do Rio de Janeiro e o projeto ético-político e profissional: relato de experiência. In: ENCONTRO NACIONAL DO SERVIÇO SOCIAL NO MINISTÉRIO PÚBLICO, 1., Anais... Porto Alegre: Ministério Público do Rio Grande do Sul, 2006. [CD-ROM.]

SIMIONATTO, Ivete. Classes subalternas, lutas de classe e hegemonia: uma abordagem gramsciana. Katálisys, Florianópolis, v. 12, n. 1, p. 41-49, jan./jun. 2009.

SONDA, Rosilene. Atuação do Serviço Social na área da saúde do trabalhador, no contexto do Ministério Público no estado do Paraná. In: ENCONTRO NACIONAL DO SERVIÇO SOCIAL NO MINISTÉRIO PÚBLICO, 1., Anais... Porto Alegre, Ministério Público do Rio Grande do Sul, 2006. [CD-ROM.]

SOUSA, Charles Toniolo de. A dimensão política da inserção do Serviço Social no Ministério Público do estado do Rio de Janeiro: questões preliminares acerca da experiência do trabalho na baixada fluminense. In: ENCONTRO NACIONAL DO SERVIÇO SOCIAL NO MINISTÉRIO PÚBLICO, 2., Brasília. Relatório final... Brasília, Ministério Público do Distrito Federal e Territórios, 2008. 